\title{
Correction to: Systematic Review and Meta-Analysis of the Change in Ghrelin Levels After Roux-en-Y Gastric Bypass
}

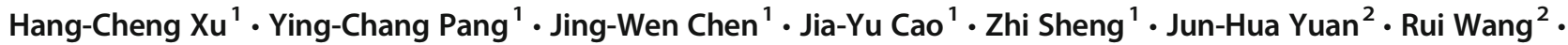 \\ Cai-Shun Zhang ${ }^{2} \cdot$ Liu-Xin Wang ${ }^{2}$. Jing Dong ${ }^{2,3}$
}

Published online: 10 April 2019

(C) The Author(s) 2019

\section{Correction to: Obesity Surgery \\ https://doi.org/10.1007/s11695-018-03686-3}

This article was initially published with incorrect copyright information. Upon publication of this correction, the copyright of this article changed to "The Author(s)." The original article has been corrected.

Publisher's Note Springer Nature remains neutral with regard to jurisdictional claims in published maps and institutional affiliations.

The online version of the original article can be found at https://doi.org/ 10.1007/s11695-018-03686-3

\footnotetext{
Jing Dong

dongjing6@hotmail.com

1 Clinical Medicine Department, Medical College, Qingdao University, Qingdao, Shandong, China

2 Special Medicine Department, Medical College, Qingdao University, Qingdao, Shandong, China

3 Physiology Department, Medical College, Qingdao University, Qingdao, Shandong, China
} 